\title{
MODEL CADANGAN KILAIM UNTUK SISTEM PEMBAYARAN INA-CBGs
}

Milla Sejahtera ${ }^{1}$, Saiful Khair ${ }^{2}$

1,2Dosen Program Studi S1 Teknik Informatika Fakultas Teknologi Informatika UTS millasejahtera@yahoo.com

\begin{abstract}
In Indonesia, national health insurance is a social security program for health protection, held by Social Security Institution of Health and all Indonesian must be participated in it. One of the payment system used to pay claims from health facilities such as hospital is Indonesia-Case Based Groups (INA-CBGs), i.e. prospective payment system which set from diagnose and procedure grouping, without count its kind and amount of health service provided. This research aims to construct the total loss model for inpatient and outpatient services in hospital using Compound model, where its claim severity model constructed from INA-CBGs tariff using simple empirical distribution. This imply that the expected value from claim severity model for this kind of payment system will be fixed, unless the tariff is revised. Whereas its frequency claim model constructed from frequency of case groups happened in hospital using Poisson distribution as a special case of Generalized Linear Models (GLM). Its total loss model can be determined using Compound model and the present value of expected value of total loss $\mathrm{PV}\left(\mathrm{E}\left[S_{t+1}\right]\right)$ will be the cost reserve that is needed to be prepared by every month. The data used in this research is inpatient and outpatient claim data during 2014 in a D-type hospital in East Nusa Tenggara.
\end{abstract}

Keywords: INA-CBGs, total loss, claim

\section{PENDAHULUAN}

Di Indonesia, jaminan kesehatan diselenggarakan oleh suatu badan yang sering dikenal dengan BPJS (Badan Penyelenggara Jaminan Sosial) Kesehatan. Berbeda dengan asuransi kesehatan pada umumnya, sistem pembayaran yang digunakan oleh BPJS Kesehatan adalah sistem pembayaran prospektif, dimana besaran biaya atas pelayanan kesehatan di fasilitas kesehatan telah ditetapkan sebelum pelayanan kesehatan tersebut terjadi di fasilitas kesehatan.

Berdasarkan fasilitas kesehatannya, sistem pembayaran klaim BPJS Kesehatan dapat dibedakan menjadi dua, yaitu:

a. Untuk pembayaran klaim kepada fasilitas kesehatan berupa puskesmas dan/atau yang setingkat, BPJS Kesehatan akan menggunakan pembayaran kapitasi yakni besaran pembayarannya akan dibayar di muka berdasarkan jumlah peserta yang terdaftar di puskesmas tersebut tanpa memperhitungkan jenis dan jumlah pelayanan kesehatan yang akan diberikan. b. Untuk pembayaran klaim kepada fasilitas kesehatan berupa rumah sakit dan/atau yang setingkat, BPJS Kesehatan akan menggunakan sistem pembayaran berbasis casemix yang kini dikenal dengan Indonesia-Case Based Groups (INACBGs).

Pembayaran klaim dengan INACBGs merupakan pembayaran klaim atas paket layanan kesehatan dimana diagnosis dan prosedur yang terjadi di rumah sakit dikelompokkan berdasarkan ciri klinis dan penggunaan sumber daya/biaya perawatan yang mirip/ sama. Karena pembayarannya berdasarkan paket layanan kesehatan, akibatnya tarif INA-CBGs yang dibayarkan BPJS Kesehatan kepada rumah sakit telah meliputi seluruh jenis pelayanan kesehatan yang diberikan tenaga medis kepada pasien (peserta BPJS Kesehatan).

Berbeda dengan pembayaran kapitasi, pembayaran dengan INA-CBGs ini walaupun besaran tarifnya telah diketahui tetapi banyaknya pembayaran yang harus dilakukan oleh BPJS Kesehatan kepada rumah sakit tidak diketahui (acak). Dengan demikian, 
diperlukan adanya suatu model untuk memprediksi cadangan biaya yang harus dipersiapkan oleh BPJS Kesehatan atas klaim-klaim yang berasal dari rumah sakit. Cadangan tersebut dapat ditaksir dari model total loss, karena BPJS Kesehatan akan membayar klaim secara sekaligus (lump-sum) kepada rumah sakit tiap selang waktu bulanan.

\section{METODOLOGI PENELITIAN}

Konstruksi Model Total Loss Menggunakan Model Compound

Model total loss pada penelitian ini terdiri dari model besar klaim dan model frekuensi klaim. Model besar klaim pada penelitian ini dikonstruksi dengan menggunakan distribusi empiris, karena besaran tarif yang digunakan pada sistem pembayaran INA-CBGs telah ditetapkan sesuai dengan Peraturan Menteri Kesehatan Republik Indonesia No. 69 Tahun 2013 Tentang Standar Tarif Pelayanan Kesehatan Pada Fasilitas Kesehatan Tingkat Pertama dan Fasilitas Kesehatan Tingkat Lanjutan Dalam Penyelenggaraan Program Jaminan Kesehatan. Sedangkan model frekuensi klaim pada penelitian ini dikonstruksi dengan menggunakan Generalized Linear Model (GLM).

Present Value Dari Nilai Harapan Total Loss Sebagai Model Cadangan Klaim Dengan menggunakan cash flow, nilai sekarang dari $\mathrm{E}[S]$ yang akan dibayarkan BPJS Kesehatan pada akhir bulan dapat ditunjukkan pada gambar berikut. 


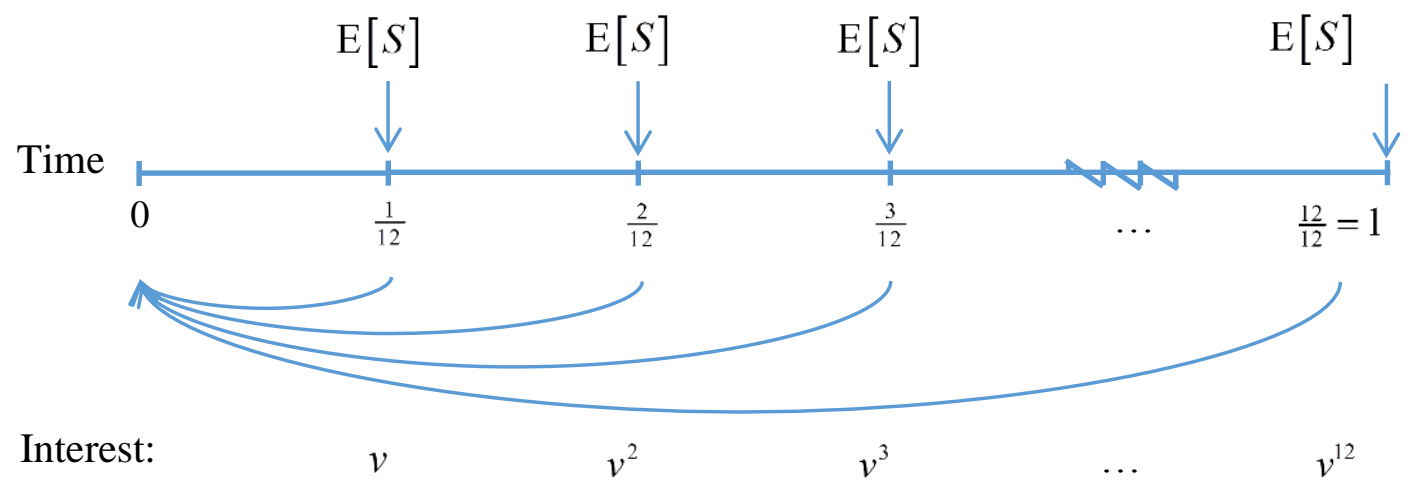

dimana:

$$
v=\frac{1}{\left(1+\frac{i^{(12)}}{12}\right)}, v^{2}=\frac{1}{\left(1+\frac{i^{(12)}}{12}\right)^{2}}, \ldots, v^{12}=\frac{1}{\left(1+\frac{i^{(12)}}{12}\right)^{12}}
$$

\section{HASIL PENELITIAN DAN PEMBAHASAN \\ Model Besar Klaim}

Misalkan $Y_{1}$ menyatakan peubah acak besar klaim yang dibayarkan BPJS Kesehatan kepada rumah sakit atas pelayanan kesehatan untuk rawat inap yang diberikan kepada peserta, $m_{1}$ dan $c_{1}$ berturut-turut menyatakan banyaknya dan besaran tarif INA-CBGs untuk pelayanan rawat inap, maka fungsi peluang untuk $Y_{1}$ dapat ditulis sebagai

$$
\operatorname{Pr}\left(Y_{1}=y\right)=\left\{\begin{array}{cc}
\frac{1}{m_{1}}, & y=c_{1} \\
0, & y \text { lainnya }
\end{array}\right.
$$

dimana $m_{1}$ dan $c_{1}$ dapat diperoleh dari tarif INA-CBGs sesuai dengan tipe rumah sakit dan regional tertentu, dengan momen pertama adalah sebagai berikut

$$
\mathrm{E}\left[Y_{1}\right]=\sum_{j=1}^{m_{1}} y_{1 j} \operatorname{Pr}\left(Y_{1}=y_{1 j}\right)=\sum_{j=1}^{m_{1}} \frac{y_{1 j}}{m_{1}}=\frac{1}{m_{1}} \sum_{j=1}^{m_{1}} y_{1 j}
$$

Dengan cara yang sama, maka fungsi peluang dan momen pertama dari model besar klaim untuk pelayanan rawat jalan, berturut-turut adalah sebagai berikut

$$
\operatorname{Pr}\left(Y_{2}=y\right)=\left\{\begin{array}{cc}
\frac{1}{m_{2}}, & y=c_{2} \\
0, & y \text { lainnya }
\end{array}\right.
$$

dimana $m_{2}$ dan $c_{2}$ dapat diperoleh dari tarif INA-CBGs sesuai dengan tipe rumah sakit dan regional tertentu, dengan momen pertama adalah sebagai berikut

$$
\mathrm{E}\left[Y_{2}\right]=\sum_{j=1}^{m_{2}} y_{2 j} \operatorname{Pr}\left(Y_{2}=y_{2 j}\right)=\sum_{j=1}^{m_{2}} \frac{y_{2 j}}{m_{2}}=\frac{1}{m_{2}} \sum_{j=1}^{m_{2}} y_{2 j}
$$

\section{Model Banyak Klaim}


Misalkan $N_{1} \mid \Lambda_{1}=\lambda_{1}$ menyatakan peubah acak banyaknya kejadian klaim untuk pelayanan rawat inap yang dipengaruhi oleh rate klaim bulanan. Rate klaim yang dimaksud adalah ukuran intensitas klaim di selang waktu yang cukup pendek [1]. Oleh karena $N_{1} \mid \Lambda_{1}=\lambda_{1}$ bergantung pada rate (yang dapat ditaksir dari data jenis kelamin, usia, length of stay, cara pulang dan kode INA-CBGs) dan kejadiannya dalam selang waktu bulanan, maka dapat diasumsikan bahwa $N_{1} \mid \Lambda_{1}=\lambda_{1}$ mengikuti distibusi Poisson, dengan fungsi peluang berikut

$$
\operatorname{Pr}\left(N_{1} \mid \Lambda_{1}=\lambda_{1}\right)=\frac{\lambda_{1}^{n_{1}} \exp \left\{-\lambda_{1}\right\}}{n_{1} !}, \quad n_{1}=0,1,2, \ldots
$$

dengan mean $\mathrm{E}\left[N_{1} \mid \Lambda_{1}=\lambda_{1}\right]=\lambda_{1}$ dan variansi $\operatorname{Var}\left[N_{1} \mid \Lambda_{1}=\lambda_{1}\right]=\lambda_{1}[2]$.

Sedangkan fungsi rate klaim bulanannya akan didefinisikan sebagai suatu fungsi yang selalu positif sebagai berikut

$$
\lambda_{1}=\exp \left\{x_{1}^{\prime} \alpha\right\} \cdot \exp \left\{\varepsilon_{1}\right\}
$$

Persamaan (6) dapat dimodelkan dengan menggunakan Generalized Linear Models, sehingga diperoleh fungsi peluang untuk $\Lambda_{1}$ sebagai berikut

$$
\begin{aligned}
f_{\Lambda_{1}}\left(\lambda_{1}\right) & =\frac{d}{d \lambda_{1}} F_{\Lambda_{1}}\left(\lambda_{1}\right)=\frac{d}{d \lambda_{1}} F_{\varepsilon_{1}}\left(\ln \left(\lambda_{1}\right)-x_{1}^{\prime} \alpha\right) \\
& =f_{\varepsilon_{1}}\left(\ln \left(\lambda_{1}\right)-x_{1}^{\prime} \alpha\right) \cdot \frac{d}{d \lambda_{1}}\left(\ln \left(\lambda_{1}\right)-x_{1}^{\prime} \alpha\right) \\
& =\frac{1}{\lambda_{1}} f_{\varepsilon_{1}}\left(\ln \left(\lambda_{1}\right)-x_{1}^{\prime} \alpha\right)
\end{aligned}
$$

Untuk memprediksi kejadian klaim di bulan mendatang akan digunakan distribusi prediktif pada Bayesian Approach. Nilai harapan dari banyaknya kejadian klaim rawat inap yang terjadi di bulan Januari 2015 (bulan ke-13) jika diketahui observasi-observasi rawat inap pada 12 bulan sebelumnya adalah

$$
\mathrm{E}\left[N_{1_{13}} \mid N_{\sim}\right]=\sum_{j=0}^{\infty} n_{1_{13} j} \operatorname{Pr}\left(N_{1_{13} j}=n_{1_{13} j} \mid N_{\sim}=n_{1_{1}}, n_{1_{2}}, \ldots, n_{1_{12}}\right)
$$

Dengan cara yang sama, maka fungsi peluang dan momen pertama dari model besar klaim untuk pelayanan rawat jalan, berturut-turut adalah sebagai berikut

$$
\operatorname{Pr}\left(N_{2} \mid \Lambda_{2}=\lambda_{2}\right)=\frac{\lambda_{2}^{n_{2}} \exp \left\{-\lambda_{2}\right\}}{n_{2} !}, \quad n_{2}=0,1,2, \ldots
$$

dengan mean $\mathrm{E}\left[N_{2} \mid \Lambda_{2}=\lambda_{2}\right]=\lambda_{2}$ dan variansi $\operatorname{Var}\left[N_{2} \mid \Lambda_{2}=\lambda_{2}\right]=\lambda_{2}[2]$.

Sedangkan fungsi rate klaim bulanannya akan didefinisikan sebagai suatu fungsi yang selalu positif sebagai berikut

$$
\lambda_{2}=\exp \left\{x_{2}^{\prime} \beta\right\} \cdot \exp \left\{\varepsilon_{2}\right\}
$$

Persamaan (10) dapat dimodelkan dengan menggunakan Generalized Linear Models, sehingga diperoleh fungsi peluang untuk $\Lambda_{2}$ sebagai berikut 


$$
\begin{aligned}
f_{\Lambda_{2}}\left(\lambda_{2}\right) & =\frac{d}{d \lambda_{2}} F_{\Lambda_{2}}\left(\lambda_{2}\right)=\frac{d}{d \lambda_{2}} F_{\varepsilon_{2}}\left(\ln \left(\lambda_{2}\right)-x_{2}^{\prime} \beta\right) \\
& =f_{\varepsilon_{2}}\left(\ln \left(\lambda_{2}\right)-x_{2}^{\prime} \beta\right) \cdot \frac{d}{d \lambda_{2}}\left(\ln \left(\lambda_{2}\right)-x_{2}^{\prime} \beta\right) \\
& =\frac{1}{\lambda_{2}} f_{\varepsilon_{2}}\left(\ln \left(\lambda_{2}\right)-x_{2}^{\prime} \beta\right)
\end{aligned}
$$

Dengan cara yang sama nilai harapan dari banyaknya kejadian klaim rawat jalan yang terjadi di bulan Januari 2015 (bulan ke-13) jika diketahui observasi-observasi rawat jalan pada 12 bulan sebelumnya

$$
\mathrm{E}\left[N_{2_{13}} \mid N_{\sim}\right]=\sum_{j=0}^{\infty} n_{2_{13} j} \operatorname{Pr}\left(N_{2_{13} j}=n_{2_{13} j} \mid \underset{\sim 2}{N}=n_{2_{1}}, n_{2_{2}}, \ldots, n_{2_{12}}\right)
$$

\section{Model Total Loss}

Peubah acak total kerugian yang harus dibayarkan BPJS Kesehatan untuk pelayanan rawat inap dan rawat jalan berturut-turut dapat didefinisikan sebagai

$$
\begin{gathered}
S_{1}=Y_{11}+Y_{12}+\ldots+Y_{1 N_{1}}=\sum_{j=1}^{N_{1}} Y_{1 j} \\
S_{2}=Y_{21}+Y_{22}+\ldots+Y_{2 N_{2}}=\sum_{j=1}^{N_{2}} Y_{2 j}
\end{gathered}
$$

Ini berarti nilai harapan dari total loss rawat inap dan rawat jalan selama tahun 2014 berturut-turut dapat diperoleh dari persamaan (2), (4), (8) dan (12).

$$
\begin{aligned}
& \mathrm{E}\left[S_{1}\right]=\mathrm{E}\left[Y_{1}\right] \mathrm{E}\left[N_{1}\right] \\
& \mathrm{E}\left[S_{2}\right]=\mathrm{E}\left[Y_{2}\right] \mathrm{E}\left[N_{2}\right]
\end{aligned}
$$

Sedangkan nilai harapan dari total loss rawat inap dan rawat jalan pada bulan Januari 2015 berturutturut dapat diperoleh dari persamaan (2), (4), (8) dan (12)

\section{Model Cadangan Klaim}

$$
\begin{aligned}
& \mathrm{E}\left[S_{1_{13}}\right]=\mathrm{E}\left[Y_{1}\right] \mathrm{E}\left[N_{1_{13}}\right] \\
& \mathrm{E}\left[S_{2_{13}}\right]=\mathrm{E}\left[Y_{2}\right] \mathrm{E}\left[N_{2_{13}}\right]
\end{aligned}
$$

Misalkan $S$ adalah peubah acak total kerugian yang dibayarkan BPJS Kesehatan atas seluruh jenis pelayanan (rawat inap dan rawat jalan) di rumah sakit dan $\theta$ adalah peubah acak yang bernilai 1 atau 2, berturut-turut tergantung pada apakah pelayanan kesehatan yang diterima merupakan rawat inap atau rawat jalan, maka

$$
\operatorname{Pr}(\theta=i)= \begin{cases}\omega_{1}, & \text { untuk } i=1 \\ \omega_{2}, & \text { untuk } i=2\end{cases}
$$

dengan $\omega_{1}$ dan $\omega_{2}$ berturut-turut menyatakan proporsi kasus yang dirawat inap dan dirawat jalan. Dengan demikian, nilai harapan dari total kerugian seluruh pelayanan selama tahun 2014 dapat diperoleh dari persamaan (15a) dan (15b) sebagai berikut

$$
\mathrm{E}[S]=\omega_{1} \mathrm{E}\left[S_{1}\right]+\omega_{2} \mathrm{E}\left[S_{2}\right]
$$

Sedangkan nilai harapan dari total kerugian seluruh pelayanan pada bulan Januari tahun 2015 (bulan ke-13) dapat diperoleh dari persamaan (16) dan (17) sebagai berikut

$$
\mathrm{E}\left[S_{13}\right]=\omega_{1} \mathrm{E}\left[S_{1_{13}}\right]+\omega_{2} \mathrm{E}\left[S_{2_{13}}\right]
$$

\section{S S N 2527-970x}


Oleh karena BPJS Kesehatan akan membayar klaim secara sekaligus (Iump-sum) untuk seluruh klaim yang terjadi dalam sebulan, maka $\mathrm{E}\left[S_{13}\right]$ menunjukkan nilai harapan dari kerugian BPJS Kesehatan yang mungkin terjadi pada bulan berikutnya (bulan ke-13). Ini berarti besarnya cadangan yang harus dipersiapkan oleh BPJS Kesehatan adalah sebesar E[ $\left.S_{13}\right]$.

Dengan menggunakan cash flow, nilai sekarang dari cadangan biaya yang harus dipersiapkan BPJS Kesehatan untuk bulan Januari 2015 adalah

$$
\mathrm{PV}=v \mathrm{E}\left[S_{13}\right]=\left(\frac{1}{1+\frac{i^{(12)}}{12}}\right) \mathrm{E}\left[S_{13}\right]
$$

sedangkan nilai sekarang dari total cadangan biaya yang harus dipersiapkan BPJS Kesehatan selama tahun 2015 adalah

$$
\mathrm{PV}=v \mathrm{E}\left[S_{13}\right]+v^{2} \mathrm{E}\left[S_{14}\right]+v^{3} \mathrm{E}\left[S_{15}\right]+\ldots+v^{12} \mathrm{E}\left[S_{24}\right]
$$

\section{KESIMPULAN}

Dari pembahasan di atas, dapat disimpulkan bahwa:

1. Untuk sistem pembayaran INA-CBGs yang besaran tarif INA-CBGs telah diketahui, dapat dimodelkan dengan distribusi empiris. Akibatnya, nilai harapan dari besar klaim $\mathrm{E}[Y]$ untuk sistem pembayaran ini akan bernilai tertentu (fixed) sepanjang tahun selama tarif INA-CBGs tersebut belum direvisi.

2. Berbeda dengan model banyak klaim dimana kejadiannya tidak tentu sehingga harus dimodelkan dengan distribusi prediktif untuk memprediksi nilai harapan dari kejadian banyak klaim yang mungkin akan terjadi bulan mendatang $\mathrm{E}\left[N_{t+1}\right]$.

3. Dari model besar dan banyak klaim di atas, dapat diperoleh model total loss BPJS Kesehatan menggunakan model compound, dimana nilai sekarang dari nilai harapan total loss $\mathrm{PV}\left(\mathrm{E}\left[S_{t+1}\right]\right)$ yang menjadi cadangan biaya yang harus dipersiapkan BPJS Kesehatan di bulan berikutnya.

Jika diketahui observasi-observasi selama 12 bulan pada tahun 2014, maka cadangan biaya tahunan yang harus dipersiapkan oleh BPJS Kesehatan dapat diperoleh dari persamaan (22).

\section{DAFTAR PUSTAKA}

[1] Kellison, Stephen G. 2009. The Theory of Interest, $3^{\text {rd }}$ Edition. McGraw-Hills Companies Inc. New York

[2] Klugman, S. A., Panjer, H. H., and Willmot, G. E. 2004. Loss Models: From Data to Decision, $2^{\text {nd }}$ Edition. John Wiley \& Sons Inc. New York

[3] Gray, R. J. and Pitts, S. M. 2012. Risk Modelling in General Insurance: From Principles to Practice. Cambridge University Press. New York

[4] Jong, Piet and Heller, Gillian. 2008. Generalized Linear Models for Insurance Data. Cambridge University Press. New York

[5] Peraturan Menteri Kesehatan Republik Indonesia No. 27 Tahun 2014 Tentang Petunjuk Teknis Sistem Indonesia Case-Based Groups

[6] Peraturan Menteri Kesehatan Republik Indonesia No. 28 Tahun 2014 Tentang Pedoman Pelaksanaan Program Jaminan Kesehatan Nasional

[7] Peraturan Menteri Kesehatan Republik Indonesia No. 69 Tahun 2013 Tentang Standar Tarif Pelayanan Kesehatan Pada Fasilitas Kesehatan Tingkat Pertama dan Fasilitas Kesehatan Tingkat Lanjutan Dalam Penyelenggaraan Program Jaminan Kesehatan 
JURNAL TAMBORA Vol 2 No 2 Agustus 2017

[8] Peraturan Presiden Republik Indonesia No. 12 Tahun 2013 Tentang Jaminan Kesehatan

[9] Peraturan Presiden Republik Indonesia No. 111 Tahun 2013 Tentang Perubahan Atas Peraturan Presiden No. 12 Tahun 2013 Tentang Jaminan Kesehatan

[10] Undang - Undang Republik Indonesia No. 24 Tahun 2011 Tentang Badan Penyelenggara Jaminan Sosial

[11] Undang - Undang Republik Indonesia No. 40 Tahun 2004 Tentang Sistem Jaminan Sosial Nasional 
JURNAL TAMBORA Vol 2 No 2 Agustus 2017 